\title{
Recent progress in CO hydrogenation over bimetallic catalysts for higher alcohol synthesis
}

Wasim U. Khan, ${ }^{[a]}$ Luqmanulhakim Baharudin, ${ }^{[b]}$ Jungkyu Choi, ${ }^{[c]}$ and Alex C. K. Yip ${ }^{*[a]}$

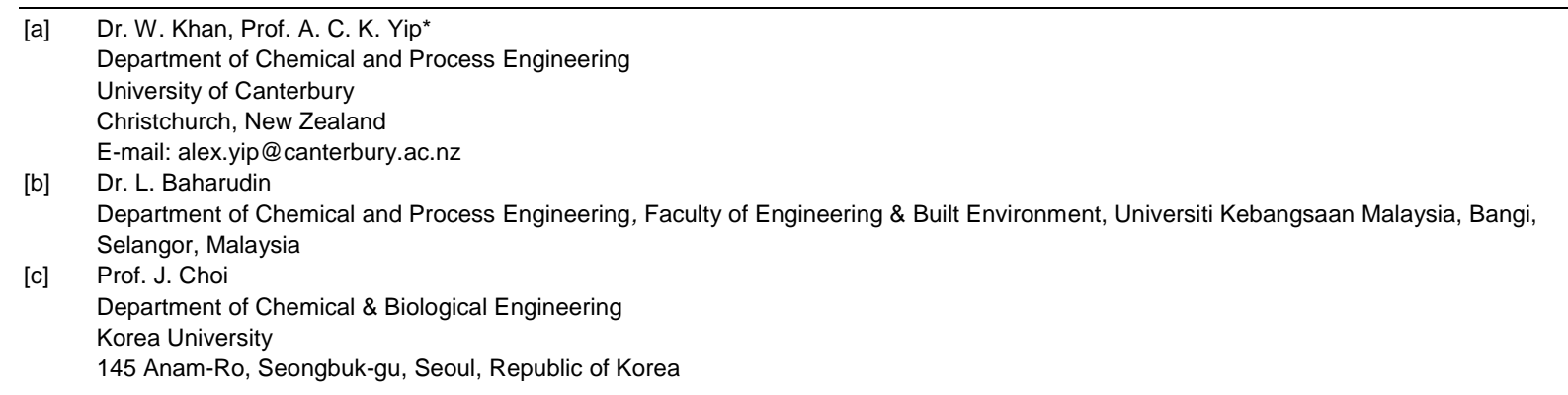

Dual active sites for higher alcohol synthesis: The synthesis of higher alcohols, which are useful chemical feedstock intermediates, from carbon monoxide hydrogenation is an attractive research area in recent years. In the bimetallic catalyst, one metal dissociates $\mathrm{CO}$ and its hydrogenation leads to chain growth, while the second metal acts as an oxygenation site. The co-existence of two active metals in close proximity helps to improve the selectivity towards higher alcohols.

\footnotetext{
Abstract: The conversion of carbon monoxide and hydrogen, generally called synthesis gas, to higher alcohols has gained recent attention. Alcohols can be either transformed into other value-added products such as ethers or used directly as fuels or fuel additives. Various types of catalysts have been prepared and investigated for the hydrogenation of $\mathrm{CO}$ to higher alcohols and improvements are in progress to find a robust catalyst with high activity and selectivity towards higher alcohols. In particular, the role of the bimetallic catalyst having two active sites contributing efficiently to higher alcohol synthesis has been a focus in recent years. Herein, the recent development in bimetallic catalyst preparation and the investigations of the reaction mechanism in $\mathrm{CO}$ hydrogenation have been reviewed.
} 


\section{Introduction}

Carbon monoxide (CO) can be hydrogenated to important products using different processes such as Fischer-Tropsch (FT) synthesis, methanol synthesis and higher alcohol synthesis (Scheme 1). ${ }^{[1]}$ Various sources, including coal, natural or shale gas and biomass, can be used to generate synthesis gas or syngas, which is a mixture of $\mathrm{CO}$ and hydrogen $\left(\mathrm{H}_{2}\right){ }^{\left[{ }^{[2]}\right.}$ The conversion of synthesis gas via FT synthesis produces hydrocarbons through carbon chain growth. In the case of higher alcohol synthesis, both chain growth and $\mathrm{CO}$ insertion are required; thus, this process needs a bimetallic catalyst having two active sites to accomplish the two tasks. ${ }^{[3]}$ Methanol production, which is the most selective industrial process of $\mathrm{CO}$ hydrogenation ${ }^{[1]}$, can be carried out at a low temperature and pressure conditions using copper-based catalysts, or at high temperature and pressure when copper-free catalysts are used. ${ }^{[4]}$

In recent years, researchers have been focusing on $\mathrm{CO}$ hydrogenation over bimetallic catalysts towards higher alcohol synthesis to produce $\mathrm{C}_{1}-\mathrm{C}_{4}$ alcohols, which may be used directly as fuels or octane-enhancing fuel additives, or be converted to other useful products such as ethers. ${ }^{[5]}$ Moreover, higher alcohols can be an alternative to conventional fossil-based fuels whose prices are increasing and sources are depleting. ${ }^{[6]}$ The main problem associated with higher alcohol synthesis from $\mathrm{CO}$ hydrogenation is the low selectivity towards alcohol, as well as catalyst stability, which prevents this idea from being used on a commercial scale. ${ }^{[7]}$ Intensive research has been conducted in recent years to find a suitable combination of two active centers in a bimetallic catalyst, which would be active, selective, and stable for higher alcohol synthesis.

Scheme 1. [Refer to the original paper]

Various review articles have been published on synthesis gas conversion, focused mainly on the production of methanol or hydrocarbons. ${ }^{[8]}$ This mini-review paper discusses the hydrogenation of carbon monoxide over bimetallic catalysts towards higher alcohol synthesis. Moreover, this review article highlights the recent progress in the development of active bimetallic centers and their roles in the reaction mechanism during higher alcohol synthesis.

\section{CO hydrogenation to higher alcohols}

The production of higher alcohols using synthesis gas is a catalytic path of significant interest. The recent advancements in synthesis gas conversion to higher alcohols have shown that various bimetallic catalysts have been investigated to achieve higher activity and selectivity towards higher alcohols. Moreover, bimetallic catalyst developments have been focused on studying the synergy between the two metals, which are required for dissociative activation and non-dissociative insertion of $\mathrm{CO}$ to generate the higher alcohols. ${ }^{\left[{ }^{[9]}\right.}$ In general, other than process parameters such as reaction temperature and gas hourly space velocity (GHSV), the catalytic performance also depends upon the catalyst preparation such as preparation technique, calcination and reduction (activation) steps, active metal, metal loading, and support material. For bimetallic catalysts, these factors include as well metal-metal ratio. In the following sections, bimetallic catalyst development and mechanistic studies for $\mathrm{CO}$ hydrogenation are discussed. 


\subsection{Catalyst development}

Because higher alcohol synthesis from CO hydrogenation mainly depends upon the catalyst type and reaction conditions, researchers have been focusing on the investigations of various types of catalysts. Four types of catalysts have been mainly reported in the literature, including alkalimodified methanol catalysts, copper-based FT catalysts, rhodium (Rh)-based catalysts and molybdenum (Mo)-based catalysts. ${ }^{[10]}$ Table 1 summarizes the various types of bimetallic catalysts used for the hydrogenation of carbon monoxide to higher alcohols studied in recent years. Among all these catalysts, copper-based catalysts have been reported to be the most attractive for higher alcohol synthesis, which can be further improved to achieve high activity and selectivity. ${ }^{[10 a]}$

\subsubsection{Effect of metal type}

Xiao et al. ${ }^{[10 a]}$ prepared unsupported copper and iron-based bimetallic nanoparticles using a coreduction method and employed these catalysts for higher alcohol synthesis from syngas. The performance of the as-prepared bimetallic nanoparticles with iron nanoparticles and physically mixed copper and iron nanoparticles were compared. Both iron and copper interacted, prior to reduction, in a way to generate copper-iron alloy, $\mathrm{CuFe}_{2} \mathrm{O}_{4}$ and $\mathrm{Cu}-\mathrm{Fe}-\mathrm{CuFe}_{2} \mathrm{O}_{4}$ interface. After the activation step, composites such as $\mathrm{Cu} / \mathrm{Fe}_{2} \mathrm{O}_{3}$ and $\mathrm{Cu} / \mathrm{FeC}_{\mathrm{x}}$ were formed, and the $\mathrm{Cu} / \mathrm{FeC} \mathrm{C}_{\mathrm{x}}$ center significantly contributed to alcohol formation, which improved $\mathrm{C}_{6+}$ alcohol selectivity.

Three-dimensional ordered macroporous copper and iron-based catalysts were synthesized using the glyoxylate route colloidal template method as highly selective catalysts towards higher alcohol formation. ${ }^{[11]}$ The improved catalytic performance of these catalysts was associated with three main factors, including the ordered structure of the catalyst providing large accessible surface area for reaction, the presence of defective nanoparticles in the form of $\mathrm{Cu}^{0}$ and $\chi-\mathrm{Fe}_{5} \mathrm{C}_{2}$ as stable and active dual sites and the synergistic effect resulting from an interaction between the $\mathrm{Cu}^{0}$ and the $\chi-\mathrm{Fe}_{5} \mathrm{C}_{2}$.

Han and his team ${ }^{[12]}$ investigated the role of layered double hydroxide-derived copper and ironbased catalysts for $\mathrm{CO}$ hydrogenation to higher alcohols. The study showed that increasing the copper-to-iron molar ratio from 0.2 to 1.0 increased the copper reduction temperature and the layer spacing until the ratio reached 0.5 , above which both parameters decreased. The catalyst having a copper to iron ratio of 0.5 was found to exhibit excellent catalytic performance with an alcohol selectivity of $20.8 \%$.

In a separate study, ${ }^{[13]}$ a series of catalysts having various copper to iron molar ratios were prepared by co-reduction and in situ coating as the preparation technique and using $\mathrm{SiO}_{2}$ as the support. The metal nanoparticles were completely coated with the mesoporous silica and increasing the copper to iron molar ratio decreased the catalytic performance. The catalyst with a copper to iron ratio of 1 exhibited excellent catalytic activity as well as higher alcohol selectivity. The higher surface area, pore volume and formation of a large amount of $\mathrm{CuFe}_{2} \mathrm{O}_{4}$, leading to strong copper to iron interaction, were reported to be the main causes for the better performance of this catalyst.

Copper and iron-based bimetallic nanoparticles were also synthesized and tested for deactivation during the conversion of synthesis gas to higher alcohols. Phase separation was observed in the bimetallic nanoparticles. Well-dispersed bimetallic nanoparticles were found in the form of monometallic copper nanoparticles, $\mathrm{Fe}_{3} \mathrm{O}_{4}$ nanorods, as well as nanoparticles of iron carbide crystallites. The phase separation influenced the copper and iron interaction and thus the catalytic 
performance, leading to lower selectivity towards higher alcohol. It was inferred that phase separation needed to be avoided for better activity. ${ }^{[14]}$

Liu and co-workers ${ }^{[15]}$ investigated the role of $\mathrm{LaCO}_{0.7} \mathrm{Cu}_{0.3} \mathrm{O}_{3}$ supported on meso-macroporous silica for $\mathrm{CO}$ hydrogenation to higher alcohols. The catalyst was transformed into core-shell structured bimetallic nanoparticles by reduction, and the structure was controlled using the reduction conditions. It was found that the catalyst with a structure comprising cobalt as the core and copper as the shell generated more alcohols compared with the structure having copper as the core and cobalt as the shell, which produced more hydrocarbons. The relatively better activity of copper as the shell and cobalt as the core was ascribed to the fact that cobalt favored hydrocarbon formation while copper promoted higher alcohol synthesis. Moreover, $\mathrm{LaCo}_{0.7} \mathrm{Cu}_{0.3} \mathrm{O}_{3}$ reduction generated $\mathrm{La}_{2} \mathrm{O}_{3}$, which played the role of promoter for higher alcohol synthesis. Furthermore, $\mathrm{La}_{2} \mathrm{O}_{3}$ improved metal dispersion as well as cobalt carbide $\left(\mathrm{CO}_{2} \mathrm{C}\right)$ formation, which in turn, improved higher alcohol synthesis. The effect of reaction temperature on the conversion of $\mathrm{CO}$ and the selectivity towards hydrocarbons, as well as higher alcohols, is shown in Figure 1.

Figure 1. [Refer to the original paper]

Gao et al. ${ }^{[16]}$ prepared layered double hydroxides-based nanoplatelets of copper, cobalt and aluminum, and embedded this metal trio on an aluminum substrate. These core-shell nanoparticles were tested for $\mathrm{CO}$ hydrogenation to produce higher alcohols. A copper to cobalt ratio of 0.5 exhibited excellent activity and selectivity. The better performance of this catalyst was associated with the unique electronic and geometric interaction between copper and cobalt, as well as with the three-dimensional hierarchical structure, which maintained catalyst stability by preventing hotspot formation and facilitating mass diffusion. Moreover, the synergy and strong interaction between the two metals also contributed positively towards enhanced catalytic activity and selectivity.

Fang et al. ${ }^{[17]}$ studied the influence of nano $\mathrm{Cu}$-Co catalysts supported on $\mathrm{LaFeO}_{3}$ for syngas conversion to higher alcohols. During pre-reduction, nano copper metal was formed due to the segregation of copper ions in the perovskite lattice. Moreover, copper ions also reduced $\mathrm{Co}_{3} \mathrm{O}_{4}$. Consequently, the catalysts with a core-shell structure having a cobalt shell covering highly dispersed copper nanoparticles supported on $\mathrm{LaFeO}_{3}$, were formed. The catalysts were highly active and selective, and their activity was ascribed to copper-modified cobalt carbide species, as well as interactions between copper, cobalt carbide, and the support.

Furthermore, Fang et al. ${ }^{[18]}$ investigated $\mathrm{CuO} / \mathrm{LaCoO}_{3}$ perovskite-derived $\mathrm{Cu}$-Co bimetallic catalysts for higher alcohol synthesis and found that highly dispersed copper increased cobalt reducibility and that the bimetallic catalyst surface was enriched due to a stronger interaction between copper and cobalt in $\mathrm{LaCoO}_{3}$ particles. It was observed that copper loaded catalysts of lower and higher than 7.5 wt\% initially exhibited a low activity and reached steady state slowly. The low activity was due to lower active sites in the lower copper loaded catalyst, and aggregation of $\mathrm{CuO}$ in the case of the higher copper loaded catalyst. In the catalyst containing $7.5 \mathrm{wt} \%$ copper, the catalytic activity decreased initially due to phase change. It then increased after $30 \mathrm{~h}$ on stream for $20 \mathrm{~h}$ as a result of interaction between the metallic copper and the cobalt carbide necessary for the higher alcohol synthesis. It was concluded that excellent activity and selectivity were the results of the modification of cobalt carbide with copper. 


\subsubsection{Effect of support type}

Apart from the active metal content, catalyst support also plays a role in the performance of a catalyst during syngas conversion to higher alcohols. The choice of the support depends mainly upon the role of the support in metal-support interaction, metal dispersion, and electronic modifications of the catalyst. Moreover, the support-inherent properties such as surface acidity/basicity and surface texture also contribute to metal dispersion, reducibility, metal-support interaction, and more importantly, catalytic performance. ${ }^{[19]}$

Cobalt and copper-based bimetallic catalysts have been reported to be strongly influenced by the type of support used. For instance, the reducibility and product selectivity of cobalt- and copperbased catalysts are affected when these metals are supported on zirconia $\left(\mathrm{ZrO}_{2}\right)$, alumina $\left(\mathrm{Al}_{2} \mathrm{O}_{3}\right)$, or lanthana $\left(\mathrm{La}_{2} \mathrm{O}_{3}\right) . \mathrm{ZrO}_{2}$ as catalyst support contributed to reducing $\mathrm{Co}^{2+}$ to metallic cobalt and assisted in achieving high selectivity towards ethanol. On the other hand, $\mathrm{Al}_{2} \mathrm{O}_{3}$ increased the interaction between the two metals and thus enhanced the selectivity. ${ }^{[20]}$

Wang and Spivey ${ }^{[20 \mathrm{a}]}$ investigated the role of $\mathrm{La}_{2} \mathrm{O}_{3}, \mathrm{Al}_{2} \mathrm{O}_{3}$ and $\mathrm{ZrO}_{2}$ support materials on copper and cobalt-based bimetallic catalysts prepared by co-precipitation technique. $\mathrm{CO}$ conversion achieved steady-state faster over the $\mathrm{Al}_{2} \mathrm{O}_{3}$ - and $\mathrm{ZrO}_{2}$-supported catalysts than that over the $\mathrm{La}_{2} \mathrm{O}_{3}$-supported catalysts. Moreover, $\mathrm{La}_{2} \mathrm{O}_{3}$-supported bimetallic catalysts exhibited lower $\mathrm{CO}$ conversion and selectivity towards higher alcohols during the $9 \mathrm{~h}$ time-on-stream. Additionally, significant changes in $\mathrm{C}_{2+}$ product selectivity were observed for $\mathrm{La}_{2} \mathrm{O}_{3}$-supported catalysts. An interesting finding for $\mathrm{La}_{2} \mathrm{O}_{3}-$ supported catalysts was the gradual increment in the selectivity towards methanol and ethanol, whose movement was opposite the direction of the selectivity towards ethane and propane. This was due to increased associatively adsorbed $\mathrm{CO}$ and decreased dissociatively adsorbed $\mathrm{CO}$.

Furthermore, the $\mathrm{La}_{2} \mathrm{O}_{3}$-supported catalysts exhibited less selectivity towards $\mathrm{C}_{2+}$ hydrocarbons due to inhibition of the FT reaction, and thus, more alcohols were produced over these catalysts. On the contrary, the $\mathrm{ZrO}_{2}$-supported catalysts exhibited a higher selectivity towards oxygenates as compared to alcohols or hydrocarbons, which was explained by hydrogenation of adjacent atomic sites, a combination of associatively adsorbed $\mathrm{CO}$ and dissociatively adsorbed CO required for oxygenates formation.

Lee et al. ${ }^{[19 a]}$ reported the effect of different supports such as aluminum, zinc and magnesium over copper and cobalt-based bimetallic catalysts for higher alcohol synthesis. It was found that zincsupported bimetallic catalysts exhibited better activity and selectivity than other supports, owing to the presence of low coordinated oxygen atoms. Temperature-programmed desorption using ammonia ( $\mathrm{NH}_{3}$-TPD) as the probe gas revealed that the zinc-supported bimetallic catalysts exhibited strong acidic sites, which was ascribed to the low coordination of the oxygen atoms. Meanwhile, the $\mathrm{NH}_{3}$-TPD for the bimetallic catalysts supported on alumina or magnesia indicated presence of weak acidic sites and consequently, these catalysts exhibited lower $\mathrm{CO}$ conversions in the activity tests. The CO hydrogenation reaction over the copper species generated methanol as an initial product, which then reacted with $\mathrm{CO}$ to yield dimethyl ether or higher alcohols. In their work, optimization of the strength of the acidic sites was performed to increase the selectivity towards higher alcohols over dimethyl ether.

\subsubsection{Effect of support treatment}

The effect of treating the support with ammonia was reported for copper and iron-based bimetallic catalysts supported on silica. The results revealed that ammonia treatment of silica support 
significantly contributed to the catalytic activity of the bimetallic catalyst. An increase in catalytic performance and alcohol yield was observed. The enhanced catalytic activity was assigned to higher iron species dispersion, increased copper ion formation and increased synergy between the copper

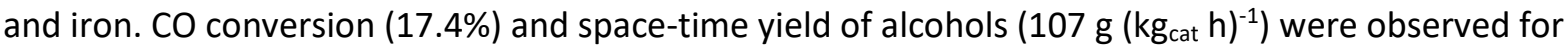
the ammonia-treated silica-supported catalysts. On the contrary, the untreated silica-supported catalysts showed $14.8 \% \mathrm{CO}$ conversion and $89 \mathrm{~g}\left(\mathrm{~kg}_{\text {cat }} \mathrm{h}\right)^{-1}$ space-time yield of alcohol. ${ }^{[21]}$

Shi and co-workers ${ }^{[22]}$ utilized carbon nanotubes as a support for copper and cobalt-based catalysts for syngas hydrogenation to higher alcohols. Their study showed a clear correlation between the pretreatment of carbon nanotubes and the catalytic performance. The pretreatment of carbon nanotubes with $68 \%$ nitric acid improved the metal dispersion and allowed the metal particles to reach tube channels. The pretreatment also improved $\mathrm{CO}$ adsorption. The nitric acid pretreated carbon nanotube-supported catalyst exhibited an increase in CO conversion (to 18\%) and alcohol yield $\left(150 \mathrm{~g}\left(\mathrm{~kg}_{\mathrm{cat}} \mathrm{h}\right)^{-1}\right)$ as compared with the untreated carbon nanotube-supported catalyst $(14.8 \%$ $\mathrm{CO}$ conversion and alcohol yield of $\left.88.4 \mathrm{~g}\left(\mathrm{~kg}_{\mathrm{cat}} \mathrm{h}\right)^{-1}\right)$.

Hydrotalcite-based bimetallic copper-cobalt nanoparticles supported on carbon fibers were also investigated for higher alcohol synthesis. The co-precipitation method was used to prepare nanocomposites of carbon fibers and layered double hydroxides, in which nanosheets of layered double hydroxides were grown over the carbon fiber surface, leading to a highly open and porous structure. The resulting catalysts, after reduction, exhibited high activity and selectivity towards higher alcohols. ${ }^{[23]}$

\subsubsection{Effect of promoter}

Wang et al. ${ }^{[24]}$ studied the influence of promoters on higher alcohol selectivity for $\mathrm{Al}_{2} \mathrm{O}_{3}$-supported bimetallic catalysts, which possess a high metal dispersion and synergy between the copper and cobalt. Among the promoters added, including potassium, magnesium, zirconium and iron, small amounts of iron and zirconium relatively improved alcohol selectivity, while potassium and magnesium influenced it negatively. As for the case of the iron promotion, its presence in a small amount significantly influenced the reducibility and the dispersion of the cobalt species. Moreover, the presence of the metallic iron species assisted in $\mathrm{CO}$ insertion and chain growth.

Earlier on, we discussed the role of iron as one of the active components in bimetallic catalysts in addition to $\mathrm{Cu}$ for higher alcohol synthesis. This is different from the promoter role in the $\mathrm{Cu}-\mathrm{Co}$ bimetallic catalysts reported by Wang et al. ${ }^{[24]}$ We note that the role of Fe (i.e., as an active component vs. as a promoter) strongly depends on the quantity of Fe present in the catalyst. When acting as an active component, Fe co-exists with $\mathrm{Cu}$ nanoparticles in close proximity, favours the formation of alcohol over hydrocarbons. ${ }^{[10 a]}$ The interpretation was further supported by others, ${ }^{[11-13]}$ where higher alcohol synthesis was favoured due to the synergetic effect of the active and stable $\mathrm{Cu}-\mathrm{Fe}$ dual sites. The physicochemical properties of the catalysts were significantly influenced by the $\mathrm{Cu} / \mathrm{Fe}$ molar ratio, which determined the interaction of $\mathrm{Cu}$ and $\mathrm{Fe},{ }^{[12-13]}$ thereby affecting the selectivity towards higher alcohols. Han et al ${ }^{[12]}$ specifically found that the tetrahedrally coordinated $\mathrm{Cu}$, as well as the spacing between the $\mathrm{Cu}$ and Fe layers, in the layered double hydroxide (LDH)derived catalyst increased with the $\mathrm{Cu} / \mathrm{Fe}$ molar ratio until it reached an optimum. A Cu/Fe ratio beyond the optimum resulted in a decrease in the metal-spacing. This volcano-shaped trend correlates well with the alcohol-to-hydrocarbon product ratios, where the optimal spacing between the $\mathrm{Cu}$ and Fe layers tends to give a higher yield of alcohol. 
On the other hand, in the case where the $\mathrm{Cu}$-Co bimetallic catalyst supported on alumina is active for higher alcohol synthesis, ${ }^{[24]}$ the addition of a small amount of Fe (approximately $1 \mathrm{wt} \%$ ) as a promoter is able to improve the metal dispersion, reducibility and the basicity of the base $\mathrm{Cu}-$ $\mathrm{Co} /$ alumina catalyst. As a result, the selectivity of alcohol is further enhanced.

\subsubsection{Effect of preparation method}

As mentioned earlier, the conversion of syngas to higher alcohols mainly depends upon the catalyst developed. The following paragraphs will cover a short description of the effect of the preparation method on the catalytic performance.

Sun et al. ${ }^{[25]}$ studied the effect of metal impregnation sequence on the catalytic activity of copper and iron-based bimetallic catalysts supported on silica. It was found that the impregnation sequence in which the silica support was first impregnated with iron and second with copper showed selectivity and space-time yield as high as $36.1 \%$ and $153.3 \mathrm{~g}\left(\mathrm{~kg}_{\text {cat }} \mathrm{h}\right)^{-1}$ respectively. The better catalytic performance was assigned to the copper surface content as well as the ratio of copper to iron surface contents.

A similar study was done by Deng et al. ${ }^{[26]}$ who investigated the performance of copper and cobaltbased bimetallic catalysts prepared with various impregnation sequences. It was suggested in their work that catalysts prepared via co-impregnation exhibited better yield and selectivity towards higher alcohols. The better performance was assigned to the synergy between the copper and cobalt.

Du et al. ${ }^{[27]}$ also studied the influence of impregnation strategy on the catalytic activity of activated carbon-supported cobalt and iron-based bimetallic catalysts for higher alcohol synthesis from syngas. The sequential impregnation, in which iron was impregnated first and copper second, exhibited better catalytic performance in comparison to co-impregnated catalysts. The higher $\mathrm{CO}$ uptake, copper surface contents and metal dispersion contributed to its better performance. Moreover, the presence of cobalt carbide and copper-cobalt alloy contributed to improving the catalytic activity in the sequentially-impregnated catalysts.

Zhang and co-workers ${ }^{[28]}$ investigated plasma-assisted preparation for iron and copper-based bimetallic catalysts supported over silica. The as-prepared catalysts (plasma-assisted and plasmauntreated) were tested for higher alcohol synthesis from syngas. The plasma assistance influenced the catalyst properties as it reduced the particle size, and enhanced metal dispersion and the concentration of copper and iron surface species. A remarkable increase in CO conversion (60.2\%) and space-time yield $\left(156.4 \mathrm{~g}\left(\mathrm{~kg}_{\text {cat }} \mathrm{h}\right)^{-1}\right)$ was observed in the plasma-assisted in comparison with the plasma-untreated catalyst, which exhibited CO conversion and space-time yield of $36.1 \%$ and $96.8 \mathrm{~g}$ $\left(\mathrm{kg}_{\mathrm{cat}} \mathrm{h}\right)^{-1}$ respectively.

Xu et al. ${ }^{[29]}$ studied the influence of a glow discharge plasma on the catalytic performance of alumina-supported copper and cobalt-based bimetallic catalysts. The plasma modification was proven to have improved the metal dispersion as well as the active metal surface contents. Plasma assistance changed the interaction between the two metals, which in turn enhanced the amount of $\mathrm{CO}$ adsorbed over the surface of the catalyst.

Table 1. [Refer to the original paper] 
The plasma-modified catalysts clearly exhibited better catalytic activity and space-time yield than conventionally impregnated catalysts.

\subsection{Mechanistic studies}

The synthesis of higher alcohols is a complicated process that depends mainly on the catalyst system and the process conditions. The catalyst can play a significant role in making the syngas conversion selective either towards higher alcohols or hydrocarbons. In general, hydrogenation of carbon monoxide leads to either hydrocarbon synthesis via FT synthesis or to methanol synthesis. On the other hand, both the abovementioned reaction mechanisms are required to produce higher alcohols. Moreover, FT synthesis promotes chain growth while methanol synthesis contributes to oxygen insertion and higher alcohol synthesis requires both of the chain growth as well as the oxygenation mechanisms. It has been reported that higher alcohol synthesis requires both dissociative and non-dissociative (or associative) $\mathrm{CO}$ activation, which needs two different metals. ${ }^{[10 \mathrm{a}]}$ Table 2 depicts the selectivity of mono-metallic cobalt and copper-based catalysts towards hydrocarbons and methanol, respectively, while the combination of both metals produces higher alcohols.

Table 2. [Refer to the original paper]

As mentioned earlier, FT facilitates carbon chain growth in which methylene inserts into alkyl groups present on the surface. These surface alkyl groups are mainly responsible for chain termination, leading to either alkanes or alkenes via dehydrogenation. For higher alcohol synthesis, nondissociative $\mathrm{CO}$ insertion occurs through the methanol synthesis process. It can be concluded that higher alcohol synthesis mainly requires a dual-site to function at an optimum level that no site should overtake the other. Otherwise, the synergy between the two metals would be less effective for higher alcohol synthesis.

The copper-based bimetallic catalysts, coupled with iron or cobalt, have been mainly studied for higher alcohol synthesis. The mechanism of CO insertion over copper-based FT catalysts is shown in Scheme $2{ }^{\left[{ }^{[37]}\right.}$ In a recent study, Athariboroujeny et al. ${ }^{[38]}$ investigated the competing mechanisms in $\mathrm{CO}$ hydrogenation over cobalt-based catalysts between $\mathrm{CO}$ insertion and $\mathrm{C}-\mathrm{C}$ coupling. Their findings led to a general conclusion that the $\mathrm{CO}$ insertion mechanism seems to be the common process. As discussed above, $\mathrm{FT}$ contributes to chain initiation $\left(\mathrm{k}_{\mathrm{d}}, \mathrm{k}_{1}\right)$ and propagation $\left(\mathrm{k}_{\mathrm{p}}\right)$. In contrary, surface alkyl groups control the chain termination either through hydrogenation or dehydrogenation $\left(\mathrm{k}_{\mathrm{H}}\right)$, leading to hydrocarbons or, through CO insertion ( $\left.\mathrm{k}_{\mathrm{co}}\right)$, leading to higher alcohol synthesis.

The same group of researchers ${ }^{[37]}$ investigated the role of the dual-site in higher alcohol synthesis. The copper, iron and cobalt-based bimetallic catalysts were employed and it was proposed that the copper-FT element center was the active dual-site for the higher alcohol synthesis. It was also revealed that iron and cobalt facilitated in carbon chain growth through methylene formation. Methylene formation resulted from $\mathrm{CO}$ dissociation and hydrogenation over the iron and the cobalt, which led to the formation of the surface alkyl groups. On the other hand, chain oxygenation occurred via non-dissociative CO adsorption over copper.

Furthermore, surface migration is also critical in achieving a high alcohol selectivity. It occurs through either (i) the surface alkyl groups on iron and cobalt migrating to copper for CO insertion, or (ii) CO migrating to iron and cobalt for surface acyl group formation, which is then hydrogenated to 
form alcohols. In either case of migration mechanisms, the role of the dual-site and their synergy is significant to control the higher alcohol selectivity. ${ }^{[37]}$

In the study by Xiao and his team ${ }^{[10 a]}$ on unsupported copper and iron-based bimetallic nanoparticles for higher alcohol synthesis, it was concluded that iron carbide species $\left(\mathrm{FeC}_{\mathrm{x}}\right)$ were found to be the active sites for $\mathrm{CO}$ dissociation as well as for carbon chain propagation. This implied that the copperiron carbide center could be considered as the dual-site. $\mathrm{CO}$ dissociative adsorption occurred on the $\mathrm{FeC}_{\mathrm{x}}$ site, leading to surface alkyl group formation through $\mathrm{CH}_{z}$ monomer initiation and propagation. First, $\mathrm{CO}$ associative adsorption occurred on the copper site. Then, the surface alkyl groups from $\mathrm{FeC}_{\mathrm{x}}$ migrated to the copper site, where $\mathrm{CO}$ was inserted into the metal-alkyl bond, forming surface acyl groups. Lastly, the surface acyl groups underwent hydrogenation to generate alcohols. The selectivity towards higher alcohols and hydrocarbons coincided with each other owing to their production from similar surface alkyl intermediates. Finally, it was concluded that the total alcohol selectivity was dependent upon the $\mathrm{Cu}-\mathrm{FeC}_{\mathrm{x}}$ interaction, and the increase in total alcohol selectivity required an increased $\mathrm{Cu}-\mathrm{FeC}_{\mathrm{x}}$ concentration. On the other hand, higher alcohol selectivity was more influenced by the nature of the $\mathrm{FeC}_{x}$, e.g., crystallite size.

Scheme 2. [Refer to the original paper]

Lu et al. ${ }^{[11]}$ reported three-dimensional macroporous Cu-Fe catalysts. The comparison between the catalytic performance of various catalysts based on selectivity, activity and Anderson-Schulz-Flory (ASF) $\alpha$-chain-growth probability postulated that the catalysts also followed the same mechanism for copper-modified FT catalysts as shown in Scheme 2. Moreover, it was shown that among $\mathrm{Cu}^{0}$ and $\mathrm{Cu}^{+}$, the former significantly contributed to the intrinsic activity of the catalysts.

The investigation of layered double hydroxide-derived, highly dispersed copper and iron-based bimetallic catalysts reported by Han et al. ${ }^{[12]}$ revealed that iron addition to copper positively influenced the product ratio between alcohols and hydrocarbons. A further increase in iron content over an optimum level adversely affected the product ratio, depicting the importance of the synergy required for higher alcohol synthesis. Moreover, increased iron content could also contribute to the structural destruction and copper oxide sintering, which reduced the contact between both metal layers, leading to loss of dual active sites. This is further explained next.

An important factor affecting the selectivity towards higher alcohols is the presence of both active metals in close proximity. Phase separation between the two metal sites could lead to lower selectivity towards alcohol, as shown in Scheme 3.

Scheme 3. [Refer to the original paper]

The core-shell copper and cobalt-based catalysts were investigated for higher alcohol synthesis. It was found that linear-type associative $\mathrm{CO}$ adsorption on copper active sites led to $\mathrm{CO}^{*}$. In contrast, dissociative bridge-type $\mathrm{CO}$ adsorption on cobalt active sites generated ${ }^{*} \mathrm{C}_{n} \mathrm{H}_{2}$ group via chain growth and hydrogenation. The surface migration of $\mathrm{CO} *$ from a $\mathrm{Cu}$ active site to ${ }^{*} \mathrm{C}_{n} \mathrm{H}_{z}$ on a Co-active site produced higher alcohols after subsequent hydrogenation. The geometric properties, such as the distance between $\mathrm{Cu}$ and $\mathrm{Co}$, played a vital role in higher alcohol selectivity. Moreover, the increased electron density of $\mathrm{Co}$, through electron transfer from $\mathrm{Cu}$ to $\mathrm{Co}$, promoted $\mathrm{CO}$ dissociation. The enhanced electron density of $\mathrm{Co}$ weakened the bond between $\mathrm{C}$ and $\mathrm{O}$, while associative $\mathrm{CO}$ adsorption increased with a decreased electron density of copper. ${ }^{[16]}$ 
Smith and co-workers ${ }^{[39 a]}$ investigated the adsorption of CO over copper- and cobalt-based monoand bimetallic catalysts through infrared spectroscopy. A new dual-site in the form of a metallic oxide cobalt pair was formed. The metallic cobalt was found to be the active site on the bimetallic $\mathrm{CuCo} / \mathrm{SiO}_{2}$ catalyst, while a cobalt pair comprising $\mathrm{Co}^{0}$ and $\mathrm{Co}^{\delta+}$ was the active site on the $\mathrm{Co} / \mathrm{SiO}_{2}$ catalyst. In the cobalt pair, metallic cobalt, i.e., $\mathrm{Co}^{0}$, served for $\mathrm{CO}$ dissociation and chain growth. $\mathrm{CO}$ associative adsorption and $\mathrm{CO}$ insertion occurred on $\mathrm{Co}^{\delta+}$, as depicted in Scheme 4. It was noted that under certain conditions, only cobalt could lead to higher alcohol synthesis through the formation of a metal oxide pair. Moreover, strong metal-support interaction and high cobalt dispersion promoted $\mathrm{Co}^{\delta+}$ surface concentration and, subsequently, the concentration of the metal oxide pair. Therefore, it can be concluded that cobalt can also play a dual-site role for higher alcohol synthesis depending upon process conditions.

This interesting finding was further supported by Chen et al. ${ }^{[40]}$ who observed the structure evolution of the $\mathrm{Co}-\mathrm{CoO}_{x}$ interface on the $\mathrm{Co} / \mathrm{CeO}_{2}$ catalysts during the reaction. It was found that $\mathrm{CO}$ dissociative adsorption was favoured on the metallic $\mathrm{Co}\left(\mathrm{Co}^{\circ}\right)$ surface, while non-dissociative $\mathrm{CO}$ adsorption was favoured on the $\mathrm{Co}^{\delta+}$ sites. The synergetic effect was accomplished over the $\mathrm{Co}-\mathrm{CoO}_{x}$ interface, i.e., the $\mathrm{Co}-\mathrm{CoO}_{x}$ pair, which was proposed to be the active sites for the higher alcohol synthesis on the $\mathrm{Co} / \mathrm{CeO}_{2}$ catalysts.

\section{Summary}

The synthesis of higher alcohols from syngas using bimetallic catalysts has made significant progress in recent years. Various combinations of active metals have been investigated. Future studies are needed to elucidate the role of the metal-support interaction, as well as the role of the metal-metal interface on the performance of the catalytic hydrogenation of carbon monoxide. Moreover, in situ and ex situ characterizations for both supported and unsupported bimetallic catalysts need to be more advanced so that the significance of the active metal centers can be established. It is also important to identify the role of each active metal during higher alcohol synthesis. A step-by-step investigation of catalyst preparation, the proximate presence of both active metals at the molecular level, adsorption and dissociation of $\mathrm{CO}$ and conversion to the final product is highly desired. Finally, more studies of the preparation method and characterization of the catalyst are required to continue developing a bimetallic catalyst that exhibits enhanced selectivity towards higher alcohols, as well as improved activity and stability in higher alcohol synthesis.

\section{References}

[1] a) H. Bai, M. Ma, B. Bai, J. Zuo, H. Cao, L. Zhang, Q.-F. Zhang, V. A. Vinokurov, W. Huang, J. Catal. 2019, 380, 68-82; b) W. U. Khan, S. S. Chen, D. C. W. Tsang, W. Y. Teoh, X. Hu, F. L. Y. Lam, A. C. K. Yip, Nano Res. 2020, 13, 533-542.

[2] W.-H. Chen, C.-Y. Chen, Appl. Energy 2020, 258, 114078.

[3] a) Z. Li, G. Luo, T. Chen, Z. Zeng, S. Guo, J. Lv, S. Huang, Y. Wang, X. Ma, Fuel 2020, 278, 118292; b) H. T. Luk, C. Mondelli, D. C. Ferre, J. A. Stewart, J. Perez-Ramirez, Chem. Soc. Rev. 2017, $46,1358-1426$.

[4] a) D. Xu, P. Wu, B. Yang, Catal. Sci. Technol. 2020, 10, 3346-3352; b) B. Balopi, P. Agachi, Danha, Procedia Manuf. 2019, 35, 367-376; c) T. Zhang, Y. Wu, X. Gao, H. Xie, G. Yang, N. Tsubaki, Y. 
Tan, Fuel 2019, 237, 1021-1028; d) P. Mohanty, K. K. Pant, S. N. Naik, J. Parikh, A. Hornung, J. N. Sahu, Renewable Sustainable Energy Rev. 2014, 38, 131-153.

[5] a) A. Masudi, N. W. C. Jusoh, O. Muraza, Catal. Sci. Technol. 2020, 10, 1582-1596; b) L. Wang, X. Gao, Y. Bai, M. Tan, K. Sun, T. Zhang, Y. Wu, J. Pan, H. Xie, Y. Tan, Fuel 2019, 253, 15701577; c) S. Fan, Y. Wang, Z. Li, Z. Zeng, S. Guo, S. Huang, X. Ma, Chin. Chem. Lett. 2020, 31, 525-529.

[6] R. G. Zhang, G. R. Wang, B. J. Wang, J. Catal. 2013, 305, 238-255.

[7] A. J. Medford, A. C. Lausche, F. Abild-Pedersen, B. Temel, N. C. Schjodt, J. K. Norskov, F. Studt, Top. Catal. 2014, 57, 135-142.

[8] a) J. J. Spivey, A. Egbebi, Chem. Soc. Rev. 2007, 36, 1514-1528; b) K. Fang, D. Li, M. Lin, M. Xiang, W. Wei, Y. Sun, Catal. Today 2009, 147, 133-138; c) M. Ao, G. H. Pham, J. Sunarso, M. O. Tade, S. Liu, ACS Catal. 2018, 8, 7025-7050.

[9] K. Xiao, X. Z. Qi, Z. H. Bao, X. X. Wang, L. S. Zhong, K. G. Fang, M. G. Lin, Y. H. Sun, Catal. Sci. Technol. 2013, 3, 1591-1602.

[10] a) K. Xiao, Z. H. Bao, X. Z. Qi, X. X. Wang, L. S. Zhong, M. G. Lin, K. G. Fang, Y. H. Sun, Catal. Commun. 2013, 40, 154-157; b) S. Zaman, K. J. Smith, Catal. Rev. 2012, 54, 41-132; c) R. Zhang, C. Wei, D. Li, Z. Jiang, B. Wang, L. Ling, M. Fan, J. Catal. 2019, 377, 1-12.

[11] Y. W. Lu, B. B. Cao, F. Yu, J. Liu, Z. H. Bao, J. S. Gao, Chemcatchem 2014, 6, 473-478.

[12] X. Y. Han, K. G. Fang, J. Zhou, L. Zhao, Y. H. Sun, J. Colloid. Interface Sci. 2016, 470, 162-171.

[13] B. Hou, X.-y. Han, M.-g. Lin, K.-g. Fang, J. Fuel Chem. Technol. 2016, 44, 217-224.

[14] K. Xiao, Z. Bao, X. Qi, X. Wang, L. Zhong, K. Fang, M. Lin, Y. Sun, J. Mol. Catal. A: Chem. 2013, 378, 319-325.

[15] G. L. Liu, T. Niu, D. M. Pan, F. Liu, Y. Liu, Appl. Catal., A 2014, 483, 10-18.

[16] W. Gao, Y. F. Zhao, H. R. Chen, H. Chen, Y. W. Li, S. He, Y. K. Zhang, M. Wei, D. G. Evans, X. Duan, Green Chem. 2015, 17, 1525-1534.

[17] Y. Z. Fang, Y. Liu, L. H. Zhang, Appl. Catal., A 2011, 397, 183-191.

[18] Y. Z. Fang, Y. Liu, W. Deng, J. H. Liu, J. Energy Chem. 2014, 23, 527-534.

[19] a) J. H. Lee, K. H. Reddy, J. S. Jung, E. H. Yang, D. J. Moon, Appl. Catal., A 2014, 480, 128-133;

b) K. G. Fang, D. B. Li, M. G. Lin, M. L. Xiang, W. Wei, Y. H. Sun, Catal. Today 2009, 147, 133-138.

[20] a) Z. Wang, J. J. Spivey, Appl. Catal., A 2015, 507, 75-81; b) J. J. Wang, P. A. Chernavskii, A. Y. Khodakov, Y. Wang, J. Catal. 2012, 286, 51-61.

[21] R. L. Lu, D. S. Mao, J. Yu, Q. S. Guo, J. Ind. Eng. Chem. 2015, 25, 338-343.

[22] Z. Le Hua, J. Zhou, J. L. Shi, Chem. Commun. 2011, 47, 10536-10547.

[23] L. F. Wang, A. Cao, G. L. Liu, L. H. Zhang, Y. Liu, Appl. Surf. Sci. 2016, 360, 77-85.

[24] J. J. Wang, P. A. Chernavskii, Y. Wang, A. Y. Khodakov, Fuel 2013, 103, 1111-1122.

[25] C. Sun, D. Mao, L. Han, J. Yu, Catal. Commun. 2016, 84, 175-178.

[26] S. Y. Deng, W. Chu, H. Y. Xu, L. M. Shi, L. H. Huang, J. Nat. Gas Chem. 2008, 17, 369-373. 
[27] H. Du, H. J. Zhu, Z. Zhao, W. D. Dong, W. T. Luo, W. Lu, M. Jiang, T. Liu, Y. J. Ding, Appl. Catal., A 2016, 523, 263-271.

[28] H. Zhang, W. Chu, H. Y. Xu, J. Zhou, Fuel 2010, 89, 3127-3131.

[29] H.-Y. Xu, W. Chu, L.-M. Shi, H. Zhang, S.-Y. Deng, J. Fuel Chem. Technol. 2009, 37, 212-216.

[30] N. Bai, Z. Gao, C. Hao, H. Deng, S. Zhang, W. Huang, ChemistrySelect 2020, 5, 6585-6593.

[31] Y. Li, W. Gao, M. Peng, J. Zhang, J. Sun, Y. Xu, S. Hong, X. Liu, X. Liu, M. Wei, B. Zhang, D. Ma, Nat. Commun. 2020, 11, 61.

[32] B. Liu, Y. Li, Y. Duan, T. Ding, Y. Tang, C. Zheng, React. Kinet., Mech. Catal. 2019, 128, 695706.

[33] S. He, W. Wang, Z. Shen, G. Li, J. Kang, Z. Liu, G.-C. Wang, Q. Zhang, Y. Wang, Mol. Catal. 2019, 479, 110610.

[34] X. Ge, H. Sun, K. Dong, Y. Tao, Q. Wang, Y. Chen, G. Zhang, P. Cui, Y. Wang, Q. Zhang, RSC Adv. 2019, 9, 14592-14598.

[35] S. J. Han, G. Park, Y.-J. Lee, K.-W. Jun, S. K. Kim, Y. T. Kim, G. Kwak, Mol. Catal. 2019, 475, 110481.

[36] C. Göbel, S. Schmidt, C. Froese, Q. Fu, Y.-T. Chen, Q. Pan, M. Muhler, J. Catal. 2020, 383, 3341.

[37] X. Xiaoding, E. B. M. Doesburg, J. J. F. Scholten, Catal. Today 1987, 2, 125-170.

[38] M. Athariboroujeny, A. Raub, V. Iablokov, S. Chenakin, L. Kovarik, N. Kruse, ACS Catal. 2019, 9, 5603-5612.

[39] a) M. L. Smith, N. Kumar, J. J. Spivey, J. Phys. Chem. C 2012, 116, 7931-7939; b) N. Kumar, G. G. Stanley, J. J. Spivey, J. Phys. Chem. C 2019, 123, 5394-5400.

[40] T.-Y. Chen, J. Su, Z. Zhang, C. Cao, X. Wang, R. Si, X. Liu, B. Shi, J. Xu, Y.-F. Han, ACS Catal. 2018, 8, 8606 